\title{
Depression and alcohol misuse among older adults: Exploring mechanisms and policy impacts using agent-based modelling
}

Ivana Stankov ${ }^{1 *}$, Yong Yang ${ }^{2}$, Brent A. Langellier ${ }^{3}$, Jonathan Purtle ${ }^{3}$, Katherine L. Nelson ${ }^{3}$, and Ana V. Diez Roux ${ }^{1}$

1. Urban Health Collaborative, Dornsife School of Public Health, Drexel University, 3600 Market St, $7^{\text {th }}$ floor, Philadelphia, PA 19104, USA

2. Division of Social and Behavioral Science, School of Public Health, University of Memphis, Memphis, TN 38117, USA

3. Department of Health Management and Policy, Dornsife School of Public Health, Drexel University, 3215 Market St, Philadelphia, PA 19104, USA

*Corresponding Author: Ivana Stankov; Email: is379@drexel.edu

\section{ABSTRACT}

Purpose.

To: 1) explore how multi-level factors impact the longitudinal prevalence of depression and alcohol misuse among urban older adults ( $\geq 65$ years), and 2 ) simulate the impact of alcohol taxation policies and targeted interventions that increase social connectedness among excessive drinkers, socially isolated and depressed older adults; both alone and in combination.

Methods.

An agent-based model was developed to explore the temporal co-evolution of depression and alcohol misuse prevalence among older adults nested in a spatial network. The model was based on Los Angeles and calibrated longitudinally using data from the Multi-Ethnic Study of Atherosclerosis.

Results.

Interventions with a social component targeting depressed and socially isolated older adults appeared more effective in curbing depression prevalence than those focused on excessive drinkers. Targeting had similar impacts on alcohol misuse, though the effects were marginal compared to those on depression. Alcohol taxation alone had little impact on either depression or alcohol misuse trajectories.

Conclusions.

Interventions that improve social connectedness may reduce the prevalence of depression among older adults. Targeting considerations could play an important role in determining the success of such efforts.

\section{Keywords}

mental health, chronic disease, social isolation, health policy, complex systems, agent-based model 


\section{INTRODUCTION}

Countries worldwide are undergoing demographic shifts toward population ageing. It is estimated that the proportion of older adults will nearly double between 2015 and 2050 [1]. For example, in North America, by 2050 , adults over 60 years are projected to comprise $27 \%$ of the population [2].

With a prevalence around 13\% [3], depression is the leading mental health issue among older adults [1]. Later-life depression is particularly concerning given its association with numerous adverse outcomes, including impaired functioning and disability, mortality, and higher rates of suicide [4-6]. Alcohol misuse (or excessive alcohol consumption [7]) is also an emerging public health problem among older people. In the United States, the proportion of older adults consuming alcohol to excess increased more than $65 \%$ in the last decade [8], and it is projected to double by 2020 [9].

Importantly, depression and alcohol misuse often coexist, but few studies have investigated their interrelationship over time [9-12]. Longitudinal studies exploring this interrelationship report significantly positive associations between depression and alcohol use, and suggest that alcohol misuse may in turn function as a significant predictor of depression trajectories [12-15] - lending support to the hypothesis that depression and alcohol misuse may be mutually reinforcing.

The dynamic relations between depression and alcohol misuse - resulting from shared risk factors, complex interactions, dependencies and feedback loops - may impact the potential effectiveness of policies seeking to curb the prevalence of these comorbid conditions. For example, the interdependent nature of these issues suggests that interventions aimed at reducing alcohol misuse (e.g., through alcohol taxation) could also impact depression prevalence. Similarly, policies or interventions aimed at reducing depression (such as strategies to reduce social isolation among older adults) could also affect alcohol use. Understanding and predicting these effects requires approaches that take into consideration the complex system of factors shaping patterns of interrelated conditions like depression and alcohol misuse.

Agent-based models (ABMs) have emerged as important tools for providing dynamic insights into the mechanisms underpinning a range of health issues and the potential impact of policies intervening on these complex systems [16]. Agent-based modelling is a computational approach that represents agents (such as people, households or businesses) with diverse characteristics, and their interactions with each other and their environment over time [17]. Governed by a set of rules, these interactions may result in changes in the environment and/ or the agents themselves, through learning and adaptive processes in 
which agents' past experiences shape their future behaviour. ABMs therefore provide an in-silico laboratory that can be used to explore the emergence of unanticipated population-level patterns that cannot be reduced to the mere sum of all individual-level interactions [17]. They are also useful in identifying the plausible impacts of diverse policies and intervention scenarios on multiple interrelated outcomes under varying conditions. Although ABMs have been used to investigate the impact of policies on behaviours like walking, physical activity and diet [16], their application to the study of interventions seeking to address mental health issues, or multiple outcomes, remains limited [18].

\section{Study purpose}

In this paper we present an ABM designed to advance understanding of depression and excessive alcohol consumption (also referred to as 'alcohol misuse' within this paper) among urban older adults, and to explore the potential impact of alcohol taxes and interventions providing opportunities for social connection, on these two outcomes. We examined taxation policies because their impact is poorly understood in the older adult demographic [19], though their effectiveness in reducing overall alcohol consumption in the general population has been well established [20]. We also decided to focus on policies aimed at enhancing social connectedness because of the high prevalence of social isolation [20] and the recent policy interest in strategies to minimize loneliness among older adults [21]. Finally, because alcohol consumption is often a social phenomenon, the joint application of both these policies could have consequences that may not be easy to predict based on empirical studies of their separate effects. This is the context where ABM may yield the most insight.

The objectives of this study were to: (1) explore the social and environmental mechanisms that may underpin the reinforcing relation between depression and alcohol misuse among urban older adults ( $\geq$ 65 years), (2) examine the potential impact of alcohol taxation policies and targeted interventions that increase social connection among excessive drinkers, socially isolated and depressed older adults, both alone and in combination, on depression and alcohol misuse.

With these objectives in mind, we delineated the boundary and scope of this model to create the simplest possible ABM capable of answering the questions of key interest to this paper. This is common practice within $A B M$ where the tension between model breadth and parsimony must be navigated in a way that "allows effective tracing from inputs via specific mechanisms to outputs of interest" [22, p.180] Specifically, we limited our focus to understanding overall population-level trajectories of depression and alcohol misuse. 


\section{METHODS}

The ABM included 540 agents (older adults $\geq 65$ years) and the alcohol outlets in their neighbourhood. Each time step (i.e., each week), agents were probabilistically assigned an alcohol consumption status (excessive drinker or not) based on individual factors, such as their affinity for excessive consumption (>7 standard drinks per week [7]) and depression (CES-D $\geq 16$ [23]), and also the alcohol consumption of their friends and cohabitants. Also considered were environmental influences, such as alcohol pricing and access to alcohol retailers. Agents' depression status was determined by considering their past predisposition toward depression, level of social connectedness and affinity toward excessive drinking. Table 1 provides a summary of the data and empirical studies used to inform these model parameters. Although important predictors of depression and alcohol use, educational attainment and gender were not included in our ABM in the interest of parsimony. Moreover, their inclusion was not deemed critical to the central aims of this paper, which were to explore the global mechanisms underpinning the interrelationship between depression and alcohol misuse, and the impact of policies on population-level trajectories of these conditions. Future modelling efforts may wish to explore these factors in more detail.

Environmental factors (i.e., price of alcohol and access to retailers) are important determinants of drinking. The model environment was therefore designed to reflect the distribution of older adults and alcohol retailers in the study region. Each agent was randomly assigned a residence on a $42 \times 56$ toroidal (i.e. donut-shaped) surface, each unit representing half a mile. These dimensions were informed by the 21 by 28-mile area of Los Angeles (LA) County inhabited by 540 older adults assessed at all exams of the Multi-ethnic Study of Atherosclerosis (MESA). MESA is a longitudinal cohort study investigating associations between lifestyle factors and cardiovascular disease across six US cities, including Los Angeles [24]. Participants between 45 and 84 years old were assessed at baseline (Exam 1) from 20002002 and followed-up at 1.5-2-year intervals (Exams 2 to 5). The LA site was the focus of this ABM because it had the largest sample of older adults with available data on depression and drinking patterns. These data were collected using the Center for Epidemiologic Studies Depression (CES-D) Scale [25] and a personal history questionnaire which sought to establish participants' usual amount of alcoholic drinks consumed per week. The use of the MESA data was approved by the Institutional Review Board at Drexel University.

The model environment was divided into two zones, one with a relatively high density of alcohol outlets (HD zone), and the other a low density (LD zone). We did not explore the impact of different types of 
alcohol outlets as this was not judged to be relevant to our main questions of interest. Supplement A1 describes the spatial data used to inform the ABM environment. Agents in each alcohol zone were uniquely assigned a weekly income based on the corresponding income distribution of older adults in MESA (see Supplement A2 for more information on the distributions used). Other individual-level characteristics assigned to agents included their cohabitation status, the excessive drinking status of their spouse/ cohabitant (if they had one), their own predisposition toward depression and excessive alcohol consumption (Table 1).

Agents were assigned social ties (i.e., to other agents within the model), representing personal networks comprising family members and close friends, as well as a level of closeness to each tie (i.e., a timeinvariant tie strength). Agents had an average of five social ties [26]. Given the influential role of environmental factors in the model, social ties were spatially constrained; the likelihood of connection between two agents was influenced by the geographic distance between their residences (the greater the distance, the less likely the existence of a connection) [27]. Supplement A3 describes the personal network and the basis for its creation in greater depth. Cohabitants were not represented as links in the spatial network, they were separately considered. 
TABLE 1 - Summary of model parameter values at baseline, and the data/ empirical sources informing these

\begin{tabular}{|c|c|c|}
\hline Parameter & Definition and values & Data and empirical foundation \\
\hline \multicolumn{3}{|c|}{ Individual attributes } \\
\hline$w_{i}$ & $\begin{array}{l}\text { Weekly income (USD/ week) } \\
w_{i} \in(24,1082)\end{array}$ & $\begin{array}{l}\text { Weekly income distributions informed by MESA. Values } \\
\text { were drawn at random, for HD zone residents, from a } \\
\text { normal distribution with mean }=215, S D=180 ; \text { and for } \\
\text { LD zone residents, from a normal distribution with mean } \\
=298, S D=257 \text {. Values remain constant. }\end{array}$ \\
\hline$S p_{i}$ & $\begin{array}{l}\text { Cohabitation status } \\
\text { Categorical } \in[0,1] \\
\text { (if lives with someone }=1 \text {; } \\
\text { else }=0 \text { ) }\end{array}$ & $\begin{array}{l}\text { Randomly assigned with proportion living with someone } \\
=0.564 \text {, informed by baseline MESA data including all LA } \\
\text { County residents. Values remain constant. }\end{array}$ \\
\hline$S p_{A i}$ & $\begin{array}{l}\text { Cohabitant's excessive alcohol } \\
\text { consumption status } \\
\text { Categorical } \in[0,1] \\
\text { (if cohabitant drinks to excess }=1 \text {; } \\
\text { else }=0 \text { ) }\end{array}$ & $\begin{array}{l}\text { Randomly assigned with proportion of cohabitants } \\
\text { drinking to excess ( }>7 \text { standard drinkers per week) }= \\
0.037 \text {, informed by baseline prevalence of excessive } \\
\text { drinking in the MESA population }(n=540) \text {. Values remain } \\
\text { constant. }\end{array}$ \\
\hline$p\left(A_{i t-1}\right)$ & $\begin{array}{l}\text { Past affinity for excessive alcohol } \\
\text { consumption } \\
p\left(A_{i t-1}\right) \in[0,1] \\
p\left(A_{i t-1}\right)=0.037 \text { at baseline }\end{array}$ & $\begin{array}{l}\text { Baseline proportion of excessive drinking ( }>7 \text { standard } \\
\text { drinkers per week) in the MESA population }(n=540 \text { ) was } \\
\text { used to initialize the model. Values updated over time. }\end{array}$ \\
\hline$p\left(A_{i t}\right)$ & $\begin{array}{l}\text { Current affinity for excessive alcohol } \\
\text { consumption } \\
p\left(A_{i t}\right) \in[0,1] \\
p\left(A_{i t}\right)=0.037 \text { at baseline }\end{array}$ & $\begin{array}{l}\text { Baseline proportion of excessive drinking ( }>7 \text { standard } \\
\text { drinkers per week) in the MESA population ( } n=540 \text { ) was } \\
\text { used to initialize the model. Values updated over time. }\end{array}$ \\
\hline$p\left(D_{i t-1}\right)$ & $\begin{array}{l}\text { Past predisposition toward } \\
\text { developing depression } \\
p\left(D_{i t-1}\right) \in[0,1] \\
p\left(D_{i t-1}\right)=0.161 \text { at baseline }\end{array}$ & $\begin{array}{l}\text { Baseline proportion of clinically depressed (CES-D > 16) } \\
\text { older adults in the MESA population ( } n=540) \text { was used to } \\
\text { initialize the model. Values updated over time. }\end{array}$ \\
\hline$p\left(D_{i t}\right)$ & $\begin{array}{l}\text { Current predisposition toward } \\
\text { developing depression } \\
p\left(D_{i t}\right) \in[0,1] \\
p\left(D_{i t}\right)=0.161 \text { at baseline }\end{array}$ & $\begin{array}{l}\text { Baseline proportion of clinically depressed (CES-D > 16) } \\
\text { older adults in the MESA population ( } n=540) \text { was used to } \\
\text { initialize the model. Values updated over time. }\end{array}$ \\
\hline$n_{S n_{i}}$ & $\begin{array}{l}\text { Number of people in agent } i^{\prime} \text { s } \\
\text { personal network }\end{array}$ & Randomly assigned. Values remain constant. \\
\hline$S_{q}$ & $\begin{array}{l}\text { Strength of tie between agent } i \text { and } \\
\text { any given agent } q \text { in its personal } \\
\text { network }\end{array}$ & $\begin{array}{l}\text { Drawn at random from uniform distribution } \in[0,1] \\
\text { Study by Onnela et al. [28]. Values remain constant. }\end{array}$ \\
\hline \multicolumn{3}{|c|}{ Environmental attributes } \\
\hline Personal ne & $\begin{array}{l}\text { Price of } 8 \text { standard drinks of alcohol } \\
\text { (USD), representing the lower range } \\
\text { of excessive weekly alcohol } \\
\text { consumption among older adults } \\
A p=\$ 13.44 \text { at baseline } \\
\text { work attributes }\end{array}$ & $\begin{array}{l}\text { Study by DiLoreto et al. [29] ] \& US recommendations for } \\
\text { alcohol consumption for those }>60 \text { year [7]. Values } \\
\text { remain constant }\end{array}$ \\
\hline & $\begin{array}{l}\text { Random spatial network with average } \\
\text { degree of connectivity = } 5 \text { people }\end{array}$ & $\begin{array}{l}\text { Study by Lambiotte et al. [27] \& Wrzus et al. [26]. } \\
\text { Remains constant. }\end{array}$ \\
\hline
\end{tabular}

HD: high density; LD: low density; SD: standard deviation; MESA: Multiethnic Study of Atherosclerosis; CES-D: Center for Epidemiologic Studies Depression Scale 


\section{Model rules}

Each simulation was run for five years (260 weeks) in Netlogo v5.3.1 [30]. Each time step (i.e., each week), agent's behaviour and depression state were updated based on a set of rules which consider the agent's past experiences and their interactions with members of their social network.

Drinking behaviour. Marital status and cohabitation have been positively associated with alcohol misuse among older adults [31-33]. A recent systematic review found a strong link between social engagement and alcohol use among older adults [34]. A core assumption in the model therefore, was that socialising predisposes to alcohol misuse. Specifically, cohabitating, particularly with a drinker [31-33], and having a high proportion of social connections that drink to excess, increased an agent' risk of alcohol misuse.

Agents' misuse was probabilistically determined by considering seven factors spanning individual, environmental and social domains: 1-2) predisposition toward excessive alcohol consumption and depression; 3) presence or absence of cohabitants and their drinking status; 4-5) drinking status and strength of ties to excessive drinkers in personal network; 6) proximity to nearest alcohol outlet; and 7) the relative cost of alcohol, which expresses alcohol price in relation to an agent's income. These parameters and the equation governing agents' drinking are detailed in Supplement A4.

Evolution of depression. An agent's predisposition to developing depression at any given time was determined by considering time-varying individual-level and social factors. Predisposition to depression and affinity for alcohol misuse increased agents' likelihood of developing depression. The combined influence of social factors, such as the size of their personal network and the average strength of social ties, simultaneously mitigated the temporal likelihood of developing depression. Supplement A4 outlines the equations and parameters governing the evolution of depression.

The CLD in Figure 1 depicts the interrelationships between excessive alcohol consumption and depression, including factors hypothesised to influence their co-evolution. 


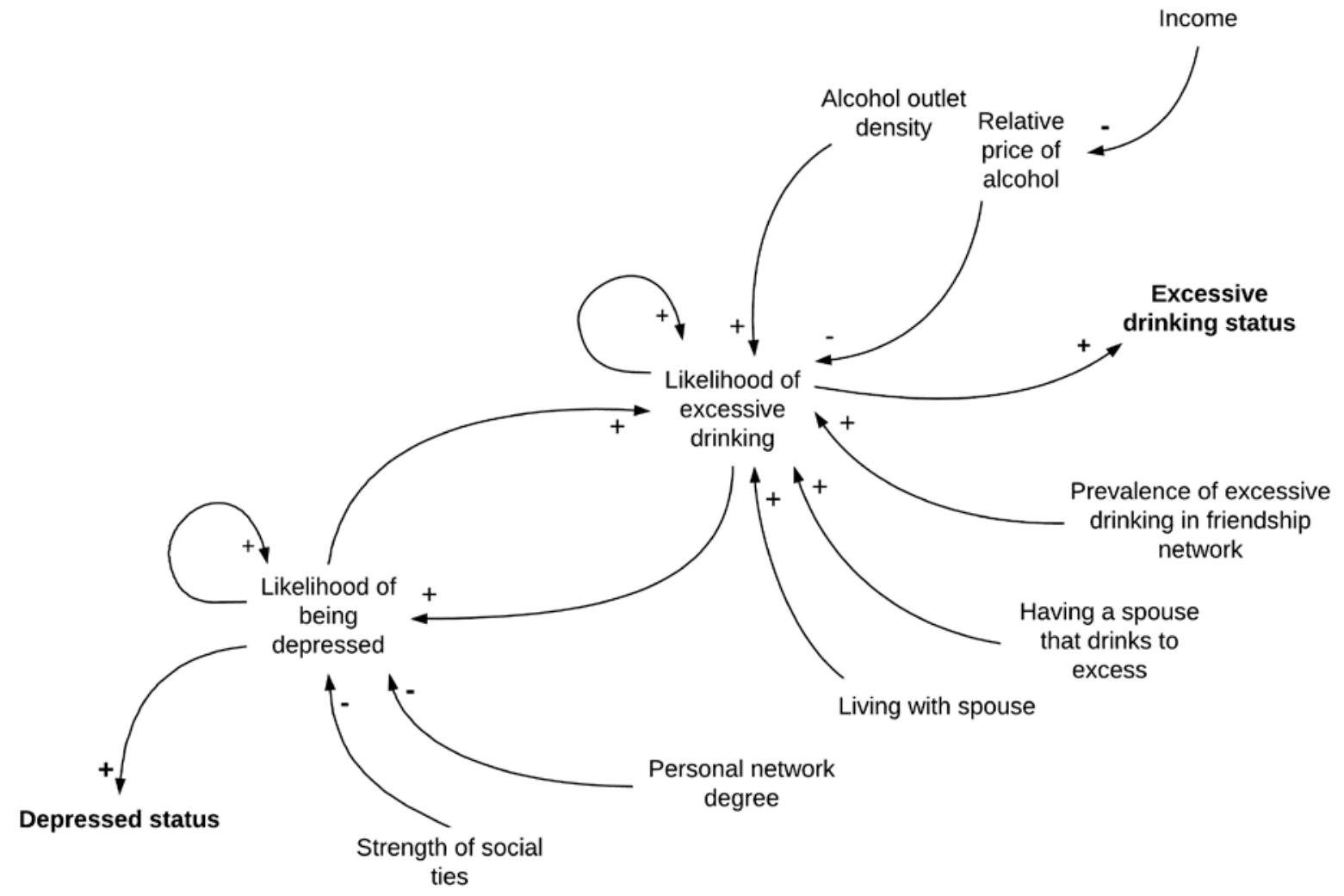

FIGURE 1 - Causal loop diagram of key factors influencing assignment of excessive drinking and depression status.

\section{Model calibration}

Parameters for the relative weights of individual $(\delta)$, social $(w S)$ and environmental $(w E)$ influences on drinking behaviour, and the characteristics of the depression function, including the intercept $(\varphi)$ and mitigating influence of social factors on depression growth $(\gamma)$ could not be informed by empirical data. Thus, plausible values of these parameters were determined through calibration. In calibration, unknown model parameters are systematically varied over a defined range to identify values that maximise the model's fit to the data [35]. Where many plausible configurations of values existed, higher weights were assigned to individual-level influences relative to social and environmental factors. This decision was based on multi-level studies which tend to show stronger and more consistent effects for individual-level compared to social and environmental factors [36]. To enable calibration, excessive alcohol consumption and depression prevalence were simulated over 5 years. These trajectories were then contemporaneously compared to 5-year depression and alcohol misuse prevalence trends among older adults residing in LA, estimated from MESA data. 


\section{Simulated policies and interventions}

We used the calibrated model to examine the potential impact of two types of intervention scenarios alcohol taxes and social connections; simulated both alone and in combination, on trends in depression and alcohol misuse.

Alcohol taxes are important policy levers [19] that can reduce alcohol consumption. The magnitude of imposed alcohol taxes varies widely by country and beverage type, ranging from no tax to as high as 85\% [37]. To account for this real-world variation, we simulated a range of taxes, including a set of extreme scenarios, representing a 50\%, $80 \%, 100 \%$ and $400 \%$ relative increase in the baseline price of alcohol $(A p)$.

We also examined the impact of social connection interventions (i.e., the impact of giving individuals one new friend) which have shown promise in reducing depression among older adults [38]. Specifically, we explored the impact of social connection on the complex dynamics between depression and drinking behaviour. For example, while reducing social isolation may lower depression risk, increasing connection to excessive drinkers may promote alcohol misuse among those previously drinking in moderation. Moreover, these relationships may themselves be modified in complex ways by alcohol taxes. Our model examined social connection interventions targeting excessive drinkers, depressed older adults, and those who were relatively isolated - defined as having fewer than average social ties. We also investigated whether connecting individuals to non-excessive drinkers, rather than randomly-selected people (i.e., regardless of alcohol misuse status), was more effective in curbing alcohol misuse and depression prevalence.

We elected to simulate policies and corresponding impacts as though they were implemented in year 2 , rather than predicting long-term impacts beyond the model's calibrated 5-year timeframe. In this way, we could compare a 'baseline trajectory' (i.e., the calibrated model run over 5 years) with alternate scenarios which represented how the observed 5-year alcohol misuse and depression prevalence trends might have been impacted had a given policy been implemented in year 2. Each policy was simulated 50 times to account for random variation.

\section{RESULTS}

The calibrated model demonstrated a good fit to 5-year depression and alcohol misuse prevalence trends estimated from MESA. The mean squared errors between the simulated output and prevalence 
rates estimated using the data were $\leq 0.06$ for both depression and excessive alcohol consumption trajectories (Figure 2).

A

${ }^{\text {A }} 20$

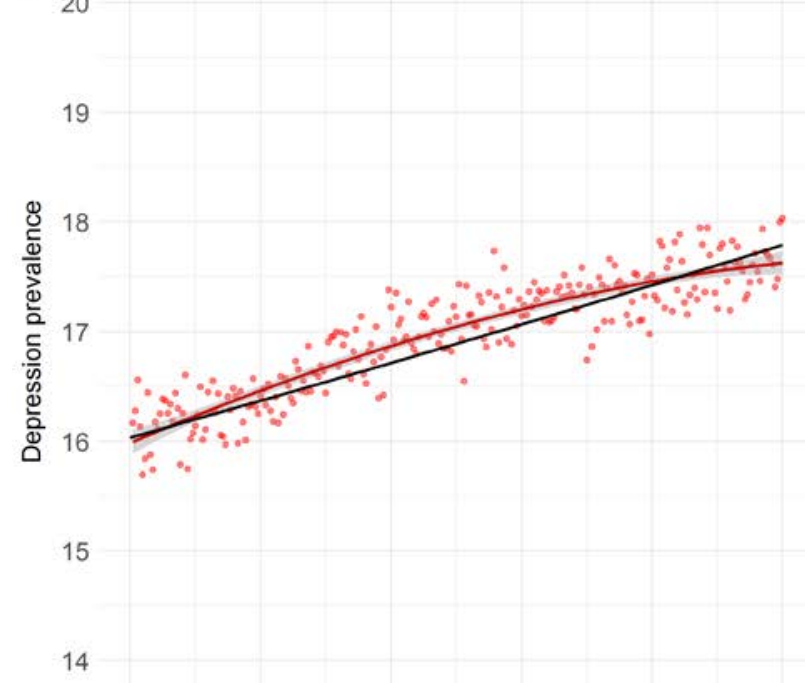

c

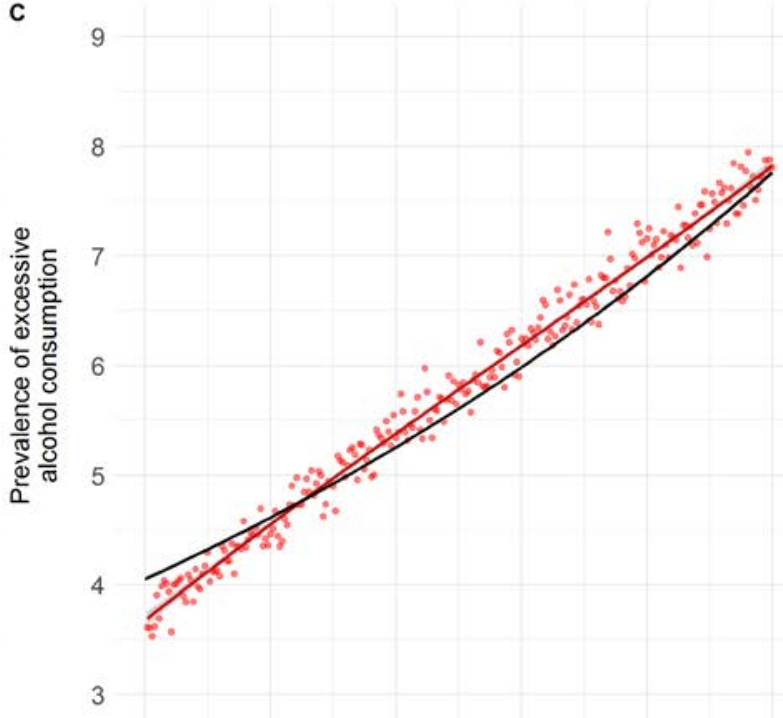

D

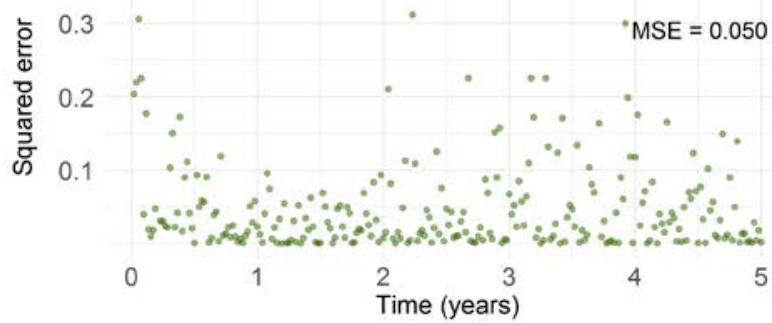

FIGURE 2 - Fit between the model simulated output and depression and excessive alcohol consumption trajectories estimated using MESA data from older adults residing in Los Angeles County. In (A) and (C) the black lines represent the trends in depression and excessive alcohol consumption prevalence estimated using the MESA data, respectively. The ABM simulated output is depicted in red. (B) and (D) depict the squared error between the data and the ABM simulated output over time, for depression and excessive alcohol consumption trajectories, respectively. The mean squared error (MSE) was 0.06 for depression and 0.05 for excessive alcohol consumption. 
The results of the alcohol tax scenarios indicate that taxation reduced alcohol consumption although the effect was small and only clearly apparent for the most extreme tax. No significant impact on the prevalence of depression was observed for any of the tax scenarios (Figure 3A-B).

The social connection interventions, which afforded agents' one additional friend, decreased depression prevalence. Of the three targeted approaches, actions directed at relatively isolated older adults appeared most effective (one percent reduction), followed by interventions targeting those with depression (Figure $3 C$ ). These two interventions were both more effective in decreasing overall depression prevalence than efforts targeting excessive drinkers. Interestingly, the impact of the social connection interventions on depression was unaffected when agents who were excessive drinkers were excluded as potential new social ties. Moreover, social connection interventions did not impact alcohol misuse (Figure 3D), even when relatively isolated individuals or excessive drinkers were connected to another person independent of drinking status.

The combined impact of the most extreme tax policy with any social connection intervention (Figure 4AB) did not appear to impact the prevalence of depression and alcohol misuse beyond levels observed from the simulated implementation of each intervention alone (Figure 4B vs 3B). Similar results were observed in analyses restricted to relatively isolated individuals (Figure 4C). However, there was some evidence that the combined strategy had a slightly smaller impact on reducing the prevalence of alcohol misuse among relatively isolated older adults, than the general population (Figure 4D compared to Figure 4B). 

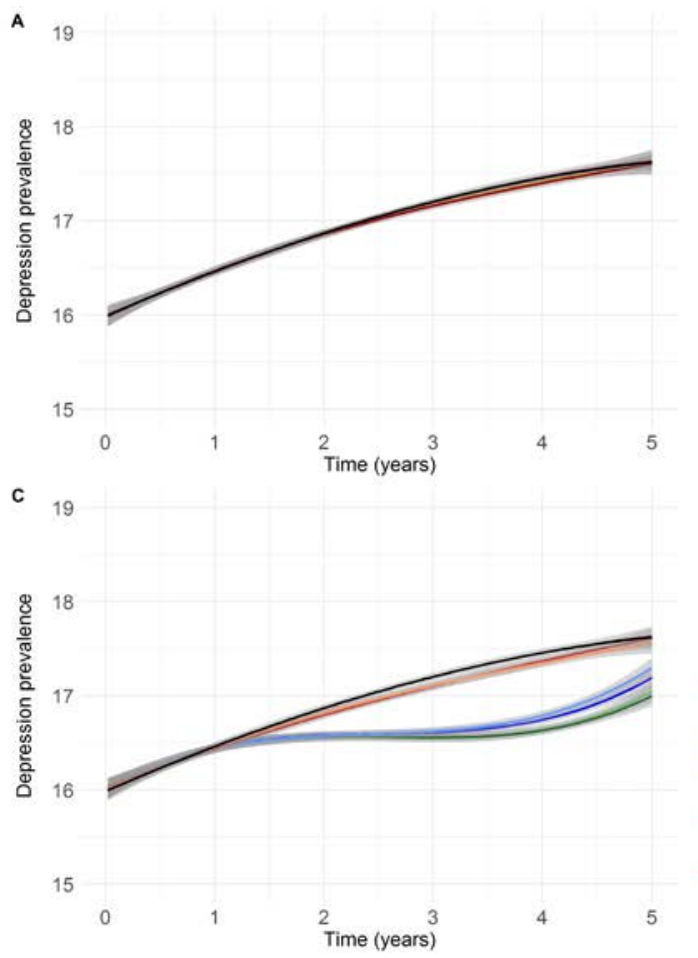

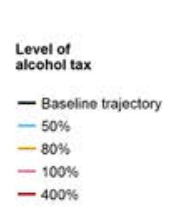

$-400 \%$

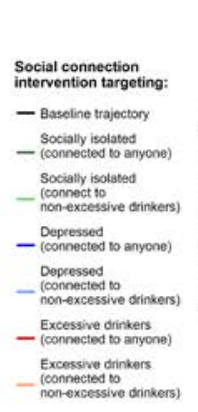

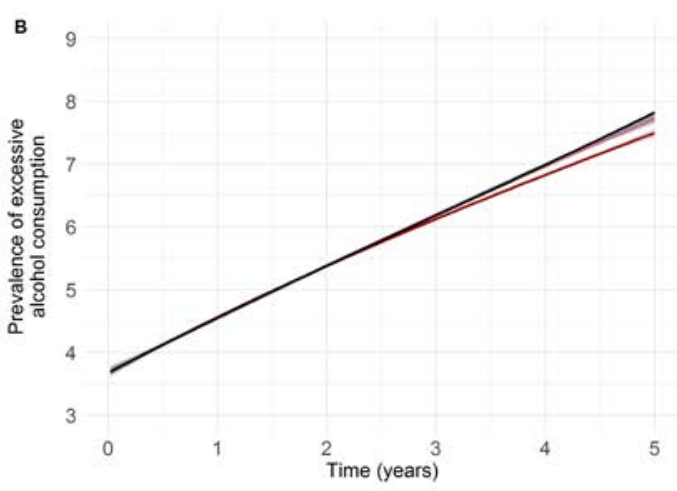

D

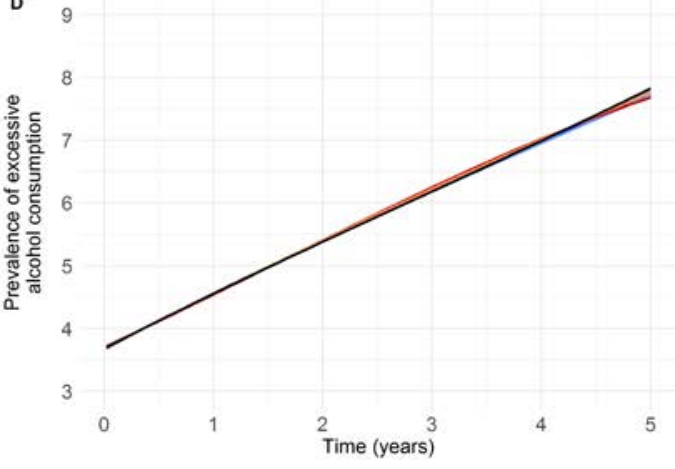

FIGURE 3 - The impact of raising alcohol taxes, in year 2, by 50\%, 80\%, 100\% and $400 \%$ on (A) overall depression and (B) alcohol misuse prevalence, and the impact of variously targeted social connection interventions, implemented in year 2, on (C) overall depression and (D) alcohol misuse prevalence.

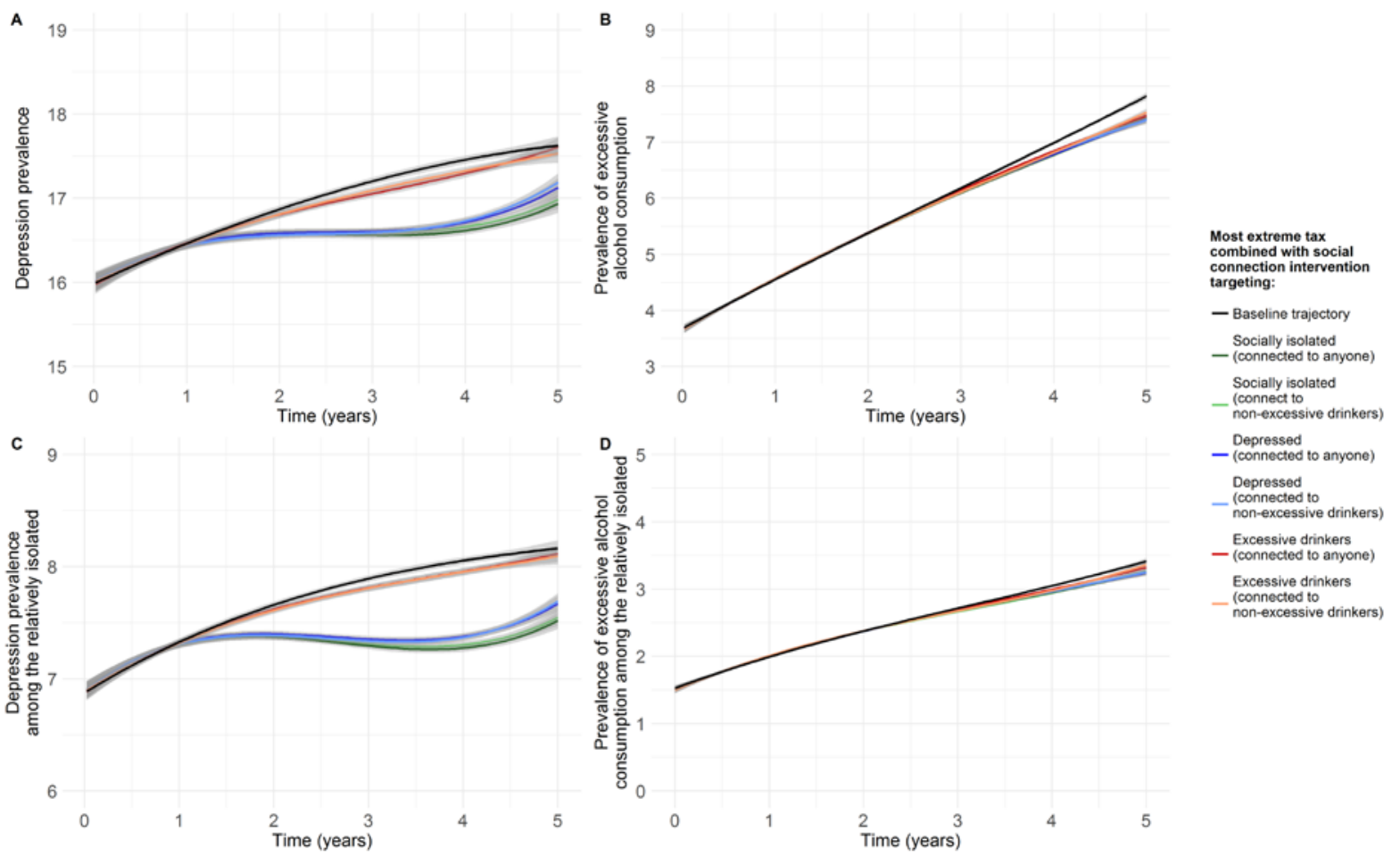

FIGURE 4 - The impact of combining variously targeted social connection interventions with the most extreme alcohol tax, in year 2 , on (A) overall depression and (B) overall alcohol misuse prevalence; and (C) depression and (D) alcohol misuse prevalence among relatively isolated older adults. 


\section{DISCUSSION}

The calibrated model successfully reproduced depression and alcohol misuse prevalence trends observed among older adults in LA. The ABMs empirical grounding and the observed alignment between the model's simulated output and the data, lends support to the mechanisms underpinning the model. Namely, the notion that depression and alcohol misuse could be interrelated and that individual, social and environmental factors plausibly influence their co-evolution. The simulated scenarios aligned with expectations: the impact of alcohol taxes was greatest on levels of alcohol misuse, while social interventions were more effective at decreasing depression prevalence [19, 38]. These findings also suggest that changes to alcohol pricing and social connectedness represent promising approaches to address depression and alcohol misuse among older adults.

The weights assigned to individual, social and environmental factors played an important role in the dynamics between depression and alcohol misuse, and in turn, on the estimated prevalence trends for drinking behaviour and depression in the model. Yet the real-world values of these parameters remain unknown. Empirical observations and calibration techniques suggested that the parameter values (e.g., the weight of influence of depression on the likelihood of alcohol misuse and vice versa) that best fit the data were quite small. This finding supports the hypothesis that depression and alcohol misuse could be interrelated but that the feedback effect may be slight.

The simulated alcohol taxes exhibited an inverse dose-response relationship with alcohol misuse; the higher the taxes, the lower the levels of alcohol misuse observed - a finding consistent with the empirical literature [39]. A systematic review by Elder et al. estimates that a 3-10\% decrease in population-level alcohol consumption may be expected for every $10 \%$ increase in alcohol cost [19]. We are unaware of any studies that evaluate alcohol price elasticity for older adults [19], and as such, it remains unclear to what extent the impacts reported by Elder et al. can be generalised to older demographics. In our simulations, alcohol misuse among older adults was less sensitive to changes in alcohol pricing than those of Elder et al. [19]. However, we caution that our model was not designed to estimate price elasticity, but to qualitatively contrast the plausible effects of various interventions. Nevertheless, an important insight was that taxation did not significantly influence depression prevalence, despite the empirically-informed relation between depression and alcohol misuse built into our model.

To date, few studies have examined the effects of increasing social connectedness on depression among older people [38]. Dickens et al. [38] report that some $40 \%$ of the 32 studies considered depression as 
an outcome in their systematic review of interventions addressing social isolation among older adults. Of these, only four reported statistically significant impacts on depression. Our ABM's findings generally align with this literature. Specifically, the simulated social interventions, which variously connected atrisk subgroups of older adults with one other person, appeared effective in decreasing depression prevalence both overall and among relatively isolated individuals. Interestingly, targeting played an important role in determining the relative effectiveness of these interventions on depression outcomes. Namely, social interventions targeting relatively isolated and depressed individuals appeared more effective, than those targeting excessive drinkers. One possible explanation for this is the relatively low prevalence of alcohol misuse among agents, resulting in the targeting of a much smaller population subset compared to the depressed and socially isolated groups. Analogously, intervention scenarios in which older adults were connected to non-excessive drinkers did not appear to be more effective in reducing the prevalence of depression than scenarios in which connections were random. This finding may also be explained by the relatively low prevalence of alcohol misuse. Specifically, social interventions which created ties between agents independent of drinking status tended to connect agents to non-excessive drinkers simply because of their high prevalence.

In contrast, none of the social interventions affected alcohol misuse. This finding is surprising as the social interventions tested directly influenced at least two factors - personal network degree and the proportion of excessive drinkers in an agent's network - implicated in the causal path between alcohol misuse and depression (as per the CLD in Figure 1). The observation that these interventions did not shift population levels of alcohol misuse, despite modest changes to depression prevalence, may reflect the relatively weak feedback mechanism found to be underpinning the co-evolution of these two outcomes. Furthermore, the fact that social interventions combined with the most extreme alcohol tax policy appeared no greater than any one of these implemented alone, could also be explained by this relatively weak feedback process.

Our model has a number of strengths, primarily, its dynamic exploration of the interrelationship between two outcomes, a focus which has been called for in public health $[17,40]$. In addition, with its focus on depression and alcohol misuse among older adults, the model affords numerous insights into the mechanisms underpinning the co-evolution of two pressing public health issues, as well as the social and environmental factors that may influence their temporal development. Further model strengths include its empirical foundations and the data-driven characterization of the environment and the agents embedded within it. The model could therefore be used to simulate the potential effectiveness 
of a range of realistic intervention scenarios on the population-level burden of these comorbid conditions. By limiting reference to a specific time frame for which data was available, the model also allowed a direct comparison between a baseline trajectory (which was well calibrated to these data) and the potential impact of simulated interventions.

The findings of this study ought to be considered with some limitations in mind. As with all ABMs, simplifying assumptions were made during model development. We assumed that alcohol misuse could be directly transmitted among individuals in the same personal network, but that depression was only indirectly transmitted through drinking behaviour. Gender, education and alcohol retailer type (i.e., onversus off-premise outlets) were not considered in the model. Another assumption was that personal networks remain static. As such, the influence of temporal changes to cohabitation and the potential impact of discordant alcohol use and depression states on the maintenance of and/or damage to social ties could not be explored. The need to calibrate the weight parameters in the model represents another limitation. While the estimated values of these parameters suggest that depression and alcohol misuse may be weakly interrelated, we cannot be certain that this finding reflects the true nature of these causal relations. More data and empirical research are required to clarify these issues.

\section{Conclusions and future directions}

This model suggests that depression and alcohol misuse are interrelated though the strength of the feedback interactions between them may not be strong. The ABM also suggests that alcohol misuse patterns among older adults may be relatively insensitive to changes in alcohol pricing. Moreover, social interventions targeting relatively isolated and depressed older adults to increase their social connectedness may be effective in reducing the prevalence of depression overall and among relatively isolated individuals.

Several important questions remain, highlighting the need for future research on older adults. First, data collection enabling empirical research of longitudinal associations between alcohol misuse and depression among older adults is required to enhance the precision of weight parameters in the model and the outcomes of simulated policy scenarios. Second, studies evaluating the impact of alcohol taxes and alcohol outlet density on drinking patterns among older adults, by gender, and across the socioeconomic spectrum, are also needed to gauge the potential effectiveness of prospective policies on alcohol misuse. Third, a dynamic exploration of social connections among older adults, including factors driving the formation and erosion of personal ties, and their influence on depression and alcohol misuse 
is required. A deeper knowledge of such mechanisms would enable a richer exploration of the interrelationship between alcohol misuse and depression in this population.

\section{REFERENCES}

1. $\quad$ World Health Organisation, Mental health of older adults: Fact sheet. 2017.

2. United Nations, Population facts: Population ageing and sustainable development. 2014, United Nations. p. 1-4.

3. Beekman, A.T.F., J. Copeland, and M.J. Prince, Review of community prevalence of depression in later life. British Journal of Psychiatry, 2018. 174(4): p. 307-311.

4. Schulz, R., et al., Association between depression and mortality in older adults: The cardiovascular health study. Archives of Internal Medicine, 2000. 160(12): p. 1761-1768.

5. Lenze, E.J., et al., The association of late-life depression and anxiety with physical disability: $A$ review of the literature and prospectus for future research. The American Journal of Geriatric Psychiatry, 2001. 9(2): p. 113-135.

6. Blazer, D.G., Depression in late life: Review and commentary. The Journals of Gerontology: Series A, 2003. 58(3): p. M249-M265.

7. Center for Substance Abuse Treatment, Substance Abuse Among Older Adults, in Treatment Improvement Protocol (TIP) Series. 1998, Substance Abuse and Mental Health Services Administration,: Rockville, MD. p. 204.

8. Grant, B.F., et al., Prevalence of 12-month alcohol use, high-risk drinking, and dsm-iv alcohol use disorder in the united states, 2001-2002 to 2012-2013: Results from the national epidemiologic survey on alcohol and related conditions. JAMA Psychiatry, 2017. 74(9): p. 911-923.

9. $\mathrm{Wu}$, L.T. and D.G. Blazer, Substance use disorders and psychiatric comorbidity in mid and later life: a review. International journal of epidemiology, 2014. 43(2): p. 304-17.

10. St John, P.D., P.R. Montgomery, and S.L. Tyas, Alcohol misuse, gender and depressive symptoms in community-dwelling seniors. International Journal of Geriatric Psychiatry, 2009. 24(4): p. 36975.

11. Devanand, D.P., Comorbid psychiatric disorders in late life depression. Biological psychiatry, 2002. 52(3): p. 236-42.

12. Brennan, P.L., et al., Alcohol use predicts 10-year depressive symptom trajectories in the Health and Retirement Study. Journal of Aging and Health, 2015. 28(5): p. 911-932.

13. Peirce, R.S., et al., A longitudinal model of social contact, social support, depression, and alcohol use. Health Psychology, 2000. 19(1): p. 28-38.

14. Hartka, E., et al., A meta - analysis of depressive symptomatology and alcohol consumption over time*. British Journal of Addiction, 2010. 86(10): p. 1283-1298.

15. Gilman, S.E. and H.D. Abraham, A longitudinal study of the order of onset of alcohol dependence and major depression. Drug \& Alcohol Dependence. 63(3): p. 277-286.

16. Nianogo, R.A. and O.A. Arah, Agent-Based Modeling of Noncommunicable Diseases: A Systematic Review. American Journal of Public Health, 2015. 105(3): p. e20-e31.

17. Tracy, M., M. Cerdá, and K.M. Keyes, Agent-based modeling in public health: Current applications and future directions. Annual Review of Public Health, 2018. 39(1): p. 77-94.

18. Langellier, B.A., et al., Complex systems approaches to understand drivers of mental health and inform mental health policy: A systematic review. Administration and Policy in Mental Health and Mental Health Services Research, 2018: p. 1-17. 
19. Elder, R.W., et al., The effectiveness of tax policy interventions for reducing excessive alcohol consumption and related harms. American Journal of Preventive Medicine, 2010. 38(2): p. 21729.

20. Wagenaar, A.C., M.J. Salois, and K.A. Komro, Effects of beverage alcohol price and tax levels on drinking: a meta-analysis of 1003 estimates from 112 studies. Addiction, 2009. 104(2): p. 179190.

21. Cox, J., Combatting loneliness one conversation at a time: A call to action. 2017, Comission on Loneliness. p. 1-21.

22. Hammond, R.A., Appendix A Considerations and best practices in agent-based modeling to inform policy, in Assessing the Use of Agent-Based Models for Tobacco Regulation, R. Wallace, A. Geller, and V. Ogawa, Editors. 2015, National Academies Press (US): Washington, DC.

23. Lewinsohn, P.M., et al., Center for Epidemiologic Studies Depression Scale (CES-D) as a screening instrument for depression among community-residing older adults. Psychology and aging, 1997. 12(2): p. 277-87.

24. Bild, D.E., et al., Multi-Ethnic Study of Atherosclerosis: objectives and design. Am J Epidemiol, 2002. 156(9): p. 871-81.

25. Radloff, L.S., The CES-D Scale: $A$ self-report depression scale for research in the general population. Applied Psychological Measurement, 1977. 1(3): p. 385-401.

26. Wrzus, C., et al., Social network changes and life events across the life span: a meta-analysis. Psychol Bull, 2013. 139(1): p. 53-80.

27. Lambiotte, R., et al., Geographical dispersal of mobile communication networks. Physica A: Statistical Mechanics and its Applications, 2008. 387(21): p. 5317-5325.

28. Onnela, J.-P., et al., Geographic Constraints on Social Network Groups. PLOS ONE, 2011. 6(4): p. e16939.

29. DiLoreto, J.T., et al., Assessment of the Average Price and Ethanol Content of Alcoholic Beverages by Brand - United States, 2011. Alcoholism, Clinical and Experimental Research, 2012. 36(7): p. 1288-1297.

30. Wilensky, U., Netlogo. 1999, Center for Connected Learning and Computer-Based Modeling, Northwestern University, Evanston, IL.

31. Hajat, S., et al., Patterns and determinants of alcohol consumption in people aged 75 years and older: results from the MRC trial of assessment and management of older people in the community. Age Ageing, 2004. 33(2): p. 170-7.

32. Kharicha, K., et al., Health risk appraisal in older people 1: are older people living alone an "atrisk" group? Br J Gen Pract, 2007. 57(537): p. 271-6.

33. Weyerer, S., et al., At-risk alcohol drinking in primary care patients aged 75 years and older. Int J Geriatr Psychiatry, 2009. 24(12): p. 1376-85.

34. Kelly, S., et al., Alcohol and older people: A systematic review of barriers, facilitators and context of drinking in older people and implications for intervention design. PLOS ONE, 2018. 13(1): p. e0191189.

35. Railsback, S.F. and V. Grimm, Agent-based and Individual-based Modeling: A Practical Introduction. 2012: Princeton University Press.

36. Brennan, P.L., R.H. Moos, and J.R. Mertens, Personal and environmental risk factors as predictors of alcohol use, depression, and treatment-seeking: A longitudinal analysis of late-life problem drinkers. Journal of Substance Abuse, 1994. 6(2): p. 191-208.

37. World Health Organisation, Global Status Report : Alcohol Policy. 2004, World Health Organisation: Geneva, Switzerland.

38. Dickens, A.P., et al., Interventions targeting social isolation in older people: a systematic review. BMC Public Health, 2011. 11(1): p. 647. 
39. Martineau, F., et al., Population-level interventions to reduce alcohol-related harm: An overview of systematic reviews. Preventive Medicine, 2013. 57(4): p. 278-296.

40. Yang, Y., Using agent - based modeling to study multiple risk factors and multiple health outcomes at multiple levels. Annals of the New York Academy of Sciences, 2017. 1408(1): p. 714.

\section{Author Contributions}

I. Stankov initiated the idea for the research, designed the agent-based model, wrote and executed the code, prepared the graphics output, wrote the first draft of the manuscript and critically revised subsequent versions of the paper. Y. Yong, B.A. Langellier, J. Purtle, K.L. Nelson and A.V. Diez Roux contributed to the conceptualization of the model, helped with methodological interpretations, gave critical feedback, and provided revisions to the manuscript.

\section{Acknowledgements and Disclosure}

Research for and preparation of this manuscript was supported by the European Union Horizon 2020 Framework Programme [grant number 667661] (Promoting mental wellbeing in the ageing populationMINDMAP). The study does not necessarily reflect the Commission's views and in no way anticipates the Commission's future policy in this area.

The MESA study was also supported by the National Heart, Lung, and Blood Institute (contracts HHSN268201500003I, N01-HC-95159, N01-HC-95160, N01-HC-95161, N01-HC-95162, N01-HC-95163, N01-HC-95164, N01-HC-95165, N01-HC-95166, N01-HC-95167, N01-HC-95168 and N01-HC-95169), the National Center for Advancing Translational Sciences (grants UL1-TR-000040, UL1-TR-001079, and UL1TR-001420), the National Heart, Lung, and Blood Institute at the National Institutes of Health (grants R01 HL071759). We thank the other investigators, staff, and participants of the MESA study for their valuable contributions. A full list of participating MESA investigators and institutions can be found at www.mesa-nhlbi.org

The authors are grateful for discussion and feedback provided by Mr Peter Lekkas.

The authors declare no conflicts of interest. 


\section{Supplement A1: Alcohol retail stores and drinking venue (or outlet) density distribution}

To develop the $A B M$, we needed to initialize a simulation environment that represented, in an abstract sense, the distribution of 540 older adults in MESA and the alcohol environment in which they lived, in Los Angeles at Exam 1. Given the absence of geospatial data relating to the number and location of alcohol outlets surrounding each participant's home, we used available data, linked to each participant, characterizing the density of alcohol outlets within a five-mile radial-buffer of their residence. We then used Kriging (a spatial interpolation method) to generate a raster surface of alcohol outlet density for the study region. For simplicity, the raster surface was divided into two zones; a high and a low alcohol retail outlet density zone (as depicted below). The average weekly income distribution of participants residing in each of these two zones was uniquely represented in the model. This was done to capture empirically established [1] disparities in alcohol outlet densities across socioeconomic strata.

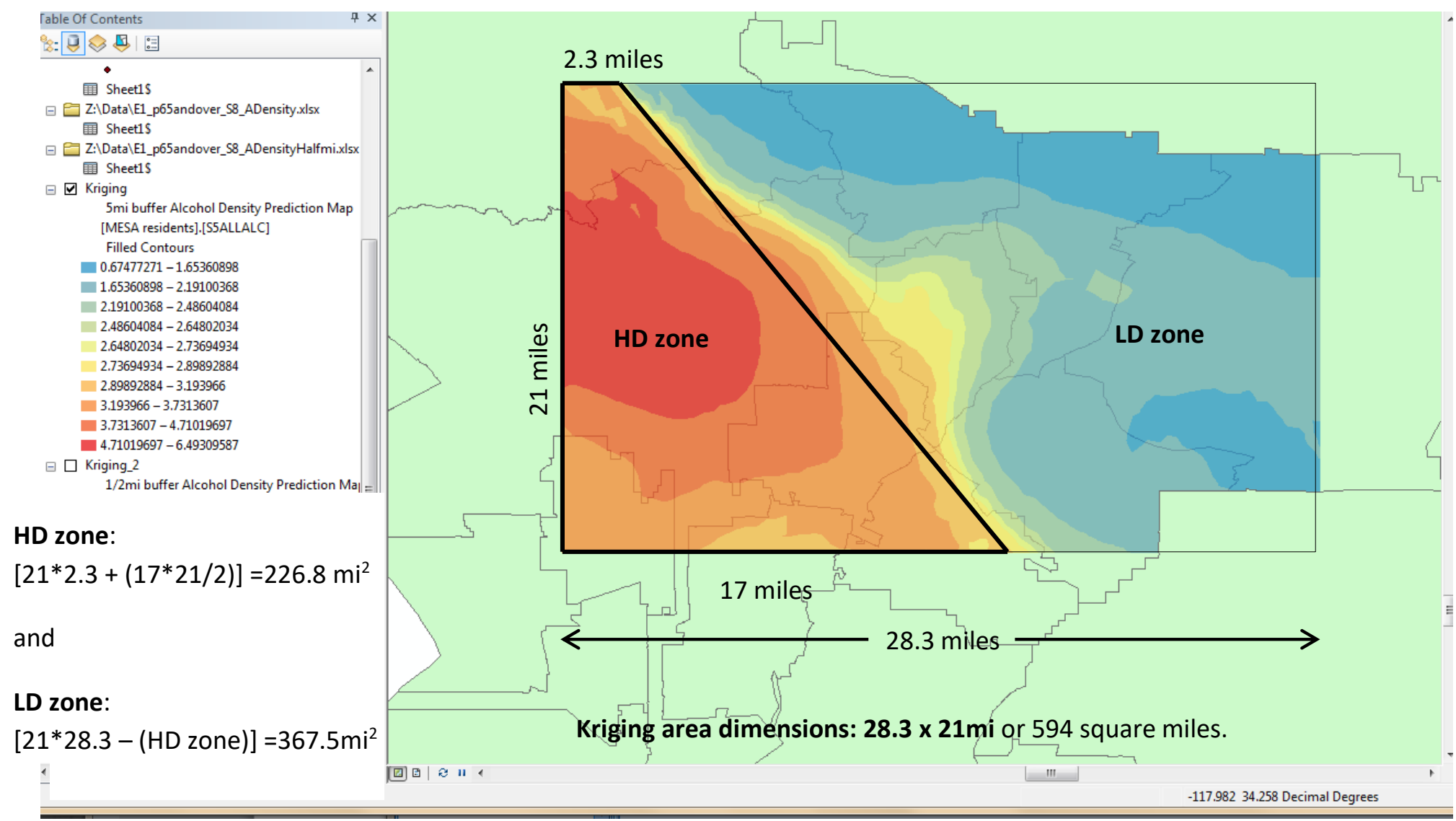

To ensure that the raster surface created using only data from older adults in MESA provided a good representation of the alcohol outlet density for the study region, we compared it to a raster surface generated using data from all MESA participants residing in LA County at Exam 1. The two raster surfaces aligned well suggesting that the MESA data restricted to older adult residents ( $\geq 65$ year old), provided a good representation of the alcohol environment of the study region at Exam 1.

The square mile ratio of high to low density (density $<2.899$ per square mile) areas was 1:1.6. This ratio and the above geographic boundaries were then used to represent, in an abstract sense, the high and low density alcohol outlet density distributions within the ABM. The $A B M$ was set up as a $56 \times 42$ torus with each square unit $=1 / 2$ mile wide. The high density zone in the $A B M$ environment was colored in red and comprised 907 units. Given that each unit $=1 / 2$ mile wide, and therefore covers an area of $1 / 4 \mathrm{mi}^{2}, 907$ units $=226.75 \mathrm{mi}^{2}$ (i.e., 907/4). This area approximates the HD zone in the map. Overall, the HD : LD ratio in the ABM environment was made to be consistent with the data i.e., 1:1.6. 


\section{ALCOHOL RETAIL OUTLET DENSITIES BY ZONE}

Given the absence of geospatial data relating to the number and location of alcohol outlets by density zone, the number of alcohol outlets represented in the model was estimated by randomly sampling from two distributions of alcohol outlet counts (one for each zone). These distributions were approximated by converting the alcohol outlet density distributions to alcohol outlet count distributions as described below.

\section{FOR THE HIGH DENSITY ZONE}

Descriptive statistics of the distribution of alcohol outlet densities within a 5 mile radius of MESA participants residing in the high density alcohol outlet zone

\begin{tabular}{llr} 
N & Valid & 191 \\
\cline { 2 - 3 } & Missing & 0 \\
\hline Mean & 4.11 \\
\hline Std. Deviation & 0.812 \\
\hline Minimum & 2.90 \\
\hline Maximum & 6.49 \\
\hline
\end{tabular}

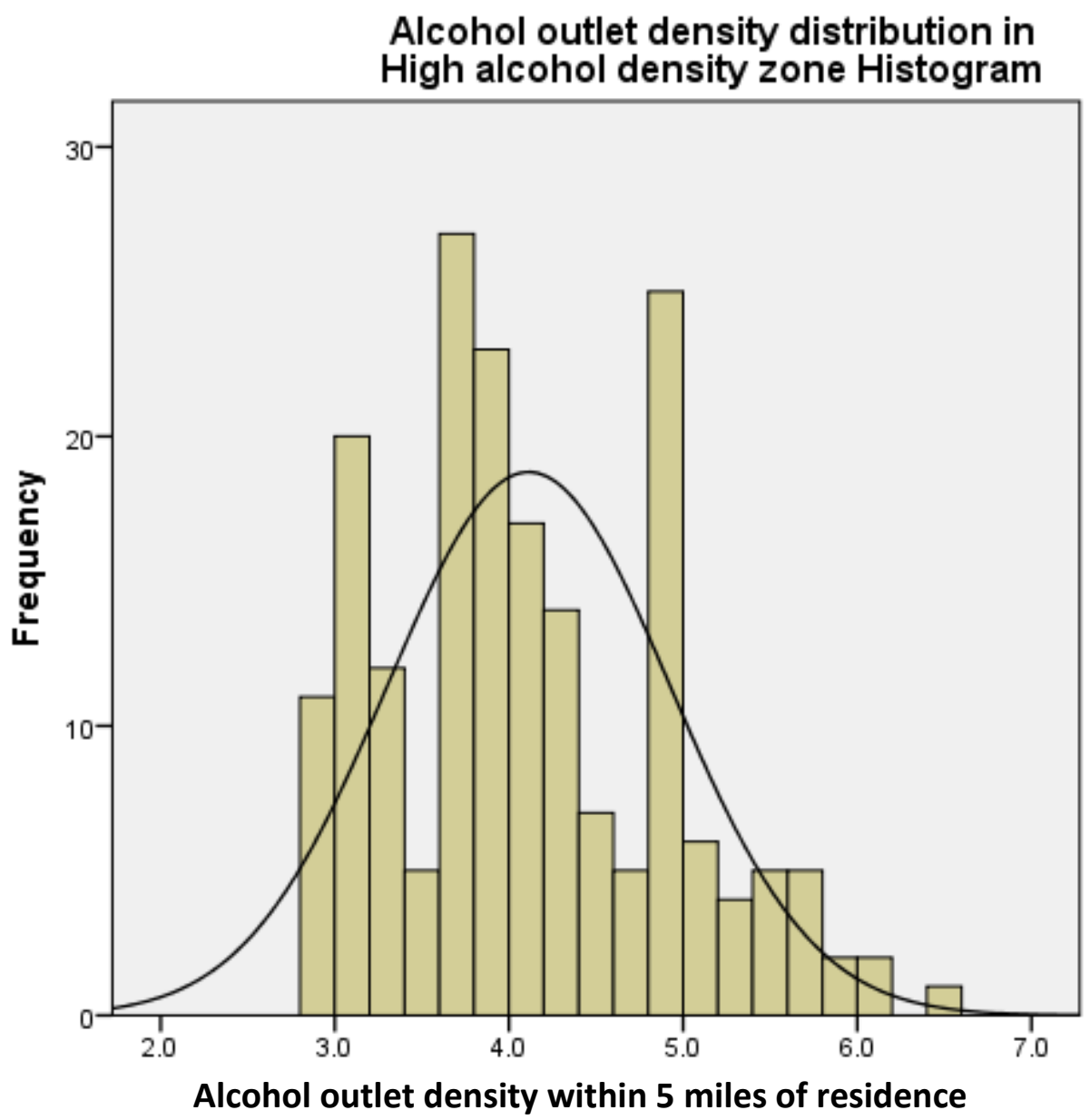

$$
\begin{aligned}
& \text { In the context of the HD zone in the ABM (where } 1 \text { unit }=1 / 4 \mathrm{mi}^{2} \text { ) } \\
& \begin{aligned}
\mu \mathrm{D}=4.11 \text { outlets per } & \mathrm{mi}^{2} \\
\text { So, } \mu \text { no. of outlets } & =4.11 \mathrm{mi}^{2} * \mathrm{HD} \text { unit area }(\mathrm{mi}) / 4 \\
& =4.11 * 907 / 4=932 \text { outlets } \\
\sigma \text { no. of outlets } & =0.812 \mathrm{mi}^{2} * 226.75 \\
& =184 \text { outlets } \\
\text { Min outlets } & =2.90 \mathrm{mi}^{2} * 226.75 \\
& =658 \text { outlets } \\
\text { Max outlets } & =6.49 \mathrm{mi}^{2} * 226.75 \\
& =1472 \text { outlets }
\end{aligned}
\end{aligned}
$$


Descriptive statistics of the distribution of alcohol outlet densities within a 5 mile radius of MESA participants residing in the low density alcohol outlet zone

\begin{tabular}{llr} 
N & Valid & 349 \\
\cline { 2 - 3 } & Missing & 0 \\
\hline Mean & 2.24 \\
\hline Std. Deviation & 0.499 \\
\hline Minimum & 0.675 \\
\hline Maximum & 2.89 \\
\hline
\end{tabular}

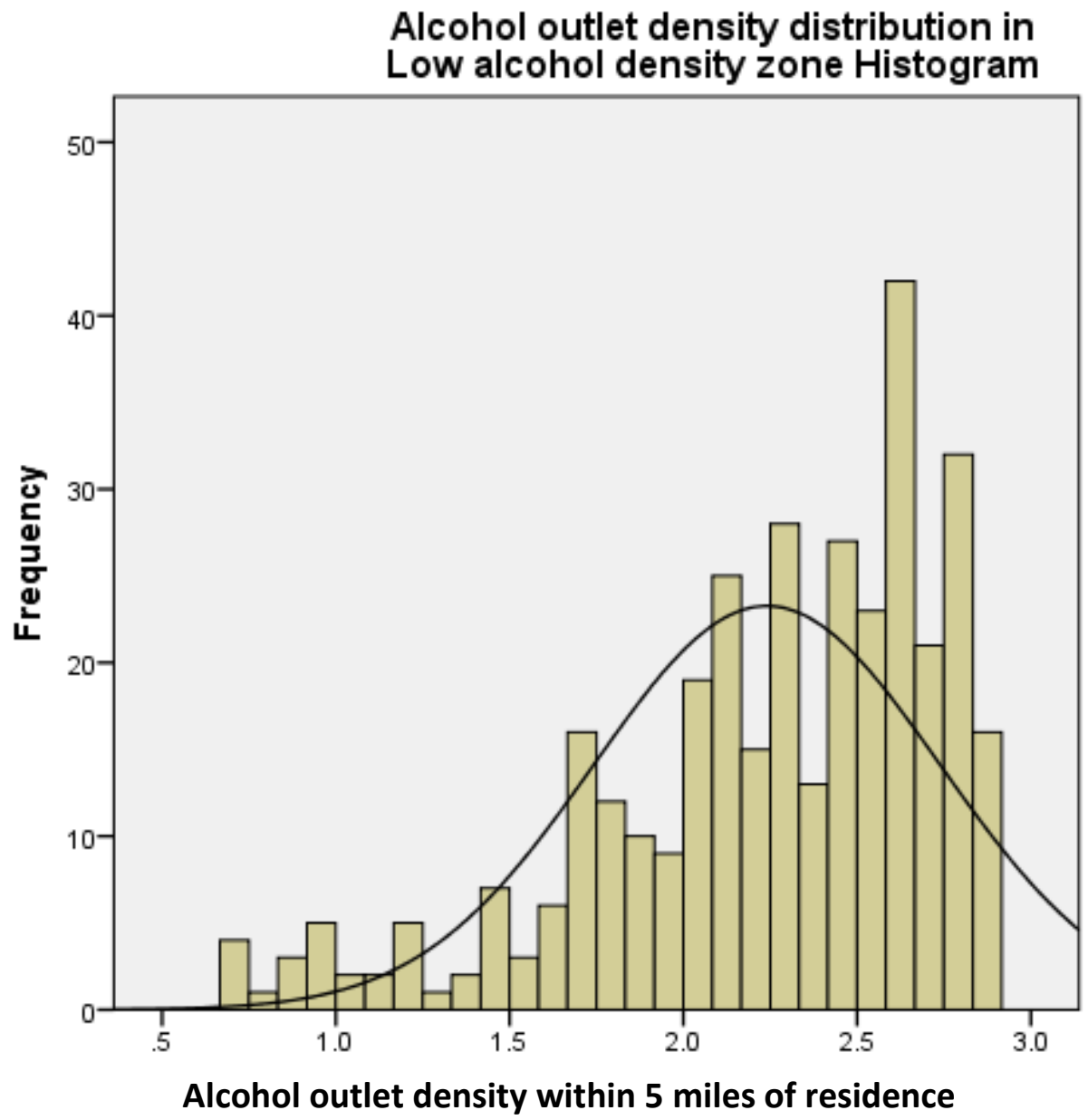

\section{References}

1. Romley, J.A., et al., Alcohol and environmental justice: The density of liquor stores and bars in urban neighborhoods in the United States. Journal of Studies on Alcohol and Drugs, 2007. 68(1): p. 48-55. 
Supplement A2: Income distribution of residents in the high and low alcohol outlet density zones, based on Exam 1 MESA data for LA County

Income as a continuous measure based on midpoint of selected category was considered. Per person weekly incomes in US dollars (USD) were calculated assuming a two person household (supported by MESA data).

\section{FOR RESIDENTS IN LOW DENSITY ZONE}

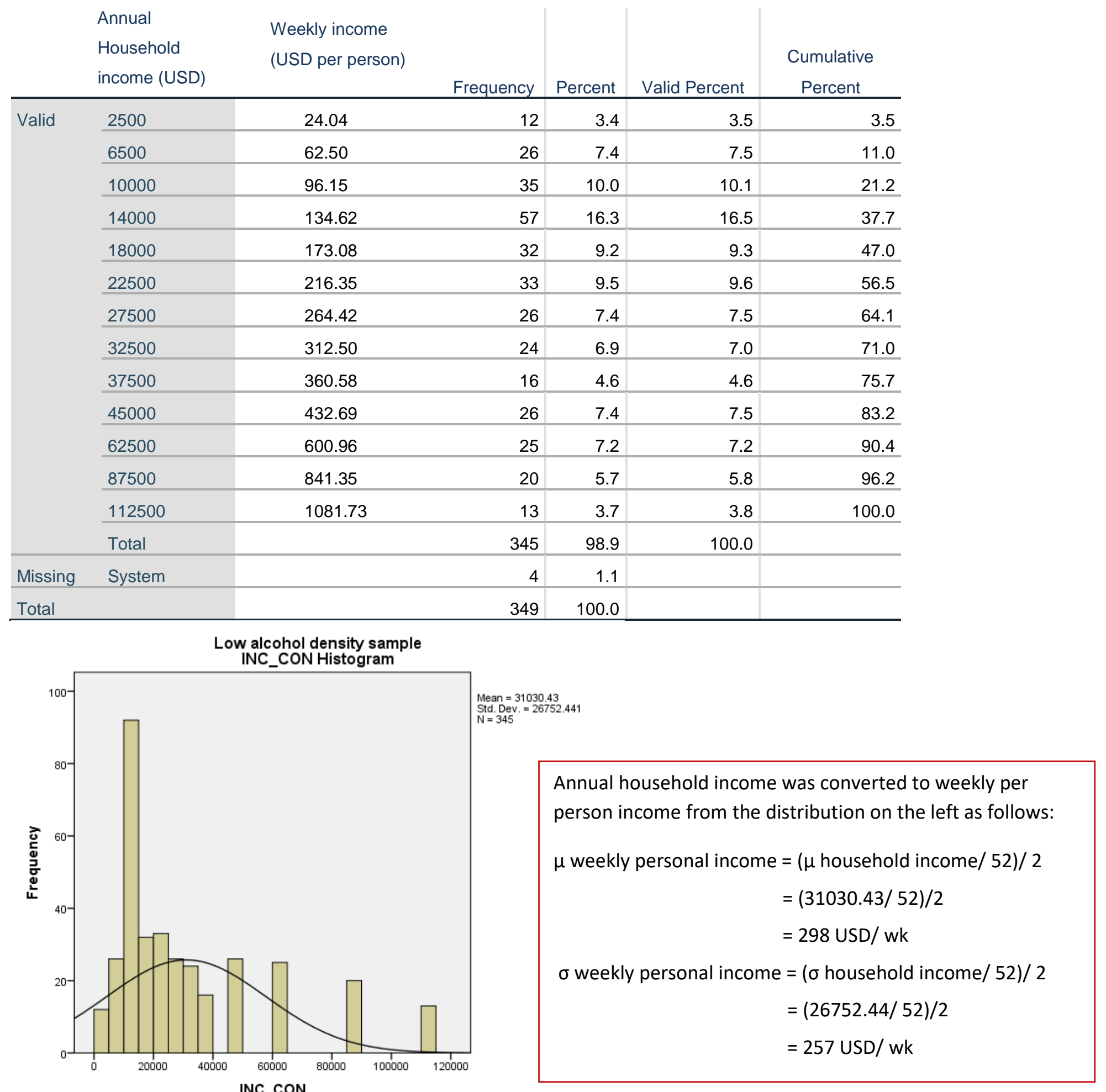




\begin{tabular}{|c|c|c|c|c|c|c|}
\hline & $\begin{array}{l}\text { Annual } \\
\text { Household } \\
\text { income } \\
\text { (USD) }\end{array}$ & $\begin{array}{l}\text { Weekly } \\
\text { income } \\
\text { (USD per } \\
\text { person) }\end{array}$ & Frequency & Percent & Valid Percent & $\begin{array}{c}\text { Cumulative } \\
\text { Percent }\end{array}$ \\
\hline \multirow[t]{14}{*}{ Valid } & 2500 & 24.04 & 8 & 4.2 & 4.3 & 4.3 \\
\hline & 6500 & 62.50 & 8 & 4.2 & 4.3 & 8.6 \\
\hline & 10000 & 96.15 & 32 & 16.8 & 17.3 & 25.9 \\
\hline & 14000 & 134.62 & 37 & 19.4 & 20.0 & 45.9 \\
\hline & 18000 & 173.08 & 27 & 14.1 & 14.6 & 60.5 \\
\hline & 22500 & 216.35 & 23 & 12.0 & 12.4 & 73.0 \\
\hline & 27500 & 264.42 & 10 & 5.2 & 5.4 & 78.4 \\
\hline & 32500 & 312.50 & 14 & 7.3 & 7.6 & 85.9 \\
\hline & 37500 & 360.58 & 8 & 4.2 & 4.3 & 90.3 \\
\hline & 45000 & 432.69 & 9 & 4.7 & 4.9 & 95.1 \\
\hline & 62500 & 600.96 & 4 & 2.1 & 2.2 & 97.3 \\
\hline & 87500 & 841.35 & 1 & .5 & .5 & 97.8 \\
\hline & 112500 & 1081.73 & 4 & 2.1 & 2.2 & 100.0 \\
\hline & Total & & 185 & 96.9 & 100.0 & \\
\hline Missing & System & & 6 & 3.1 & & \\
\hline Total & & & 191 & 100.0 & & \\
\hline
\end{tabular}

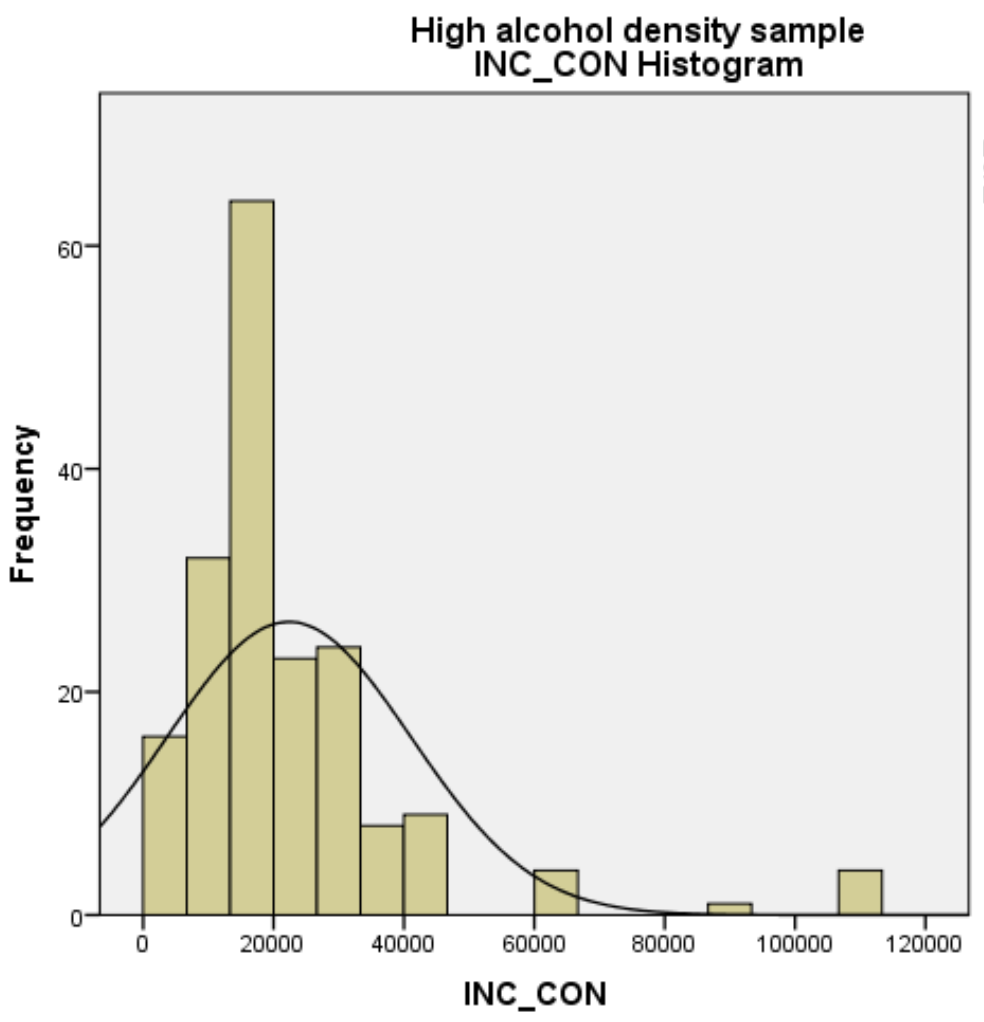

Mean $=22356.76$
Std. Dev. $=18722.147$

$N=185$

Annual household income was converted to weekly per person income from the distribution on the left as follows:

$\mu$ weekly personal income $=(\mu$ household income $/ 52) / 2$

$$
\begin{aligned}
& =(22356.76 / 52) / 2 \\
& =215 \mathrm{USD} / \mathrm{wk}
\end{aligned}
$$

$\sigma$ weekly personal income $=(\sigma$ household income $/ 52) / 2$

$$
\begin{aligned}
& =(18722.15 / 52) / 2 \\
& =180 \text { USD } / \mathrm{wk}
\end{aligned}
$$




\section{Supplement A3: Social Network formation \& associated assumptions}

Agents in the model are connected through spatially-constrained networks. These networks are important because social connections, particularly social isolation, are important determinants of depression. Drinking behaviors too may be spread through social influence. The spatially-constrained personal networks within the ABM were informed by a number of important characteristics of real-world networks observed among older adults, including spatial extent, network degree and strength of ties. Each of these attributes is described below.

- Personal networks "describes a subnetwork of closer, personal relationships in the global network such as family members, friends, and other close confidants" will form the focus of modeling efforts. The decision to represent this type of network within the ABM environment, as opposed to a broader social network, is grounded in the idea that personal networks function as resources, enabling "exchange of support among closer network members" [1, p.54].

- To create a spatially-constrained network topology, agents are randomly distributed in space and the probability that any pair of agents is connected (or that they are members of the same personal network) is a function of the distance between them. Specifically, the greater the distance between any given pair of agents, the less likely it is that they are connected. This spatial conditioning of network connections is in keeping with empirical research [2] characterizing the spatial separation of users of a mobile phone network in Belgium. Within their study, Lambiotte et al. [2] investigated the probability $p\left(C_{i j}\right)$ that any two members $i$ and $j$ of the same phone network, separated by a given distance $d$ (with a spatial resolution of $5 \mathrm{~km}$ ), are connected (as evidenced by an exchange of at least six calls/ texts within a six month period). The authors conclude that the probability of connection $p(C)$ is well approximated by:

$$
p\left(C_{i j}\right) \propto \frac{1}{d^{2}}
$$

This approximation was used to inform the probability that agent $i$ is connected to any given agent in its neighborhood $N_{i}$. That is, the probability that agent $j$ - geographically separated from agent $i$ by distance $d$ - is a member of agent $i$ 's personal network is given by:

$$
\forall j \in N_{i}, \quad p\left(C_{j}\right)=\frac{\frac{1}{d_{j}^{2}}}{\sum_{q \in S n_{i}} \frac{1}{d_{q}{ }^{2}}}
$$

An assumption intrinsic to this process is that spatial separation plays an analogous role in determining the likelihood of personal network connections as it does on social network connections, the latter being the focus of Lambiotte et al.'s paper [2]. Assumed also is the fact that the social/ personal networks of older people are spatially comparable to those of the general population.

- Average friendship network size (or degree of connectivity) of any given agent's friend network is informed by Wrzus et al.'s [1] meta-analysis. Within this review, including 277 studies, the average personal network size for people aged 65 years was found to be around 5 people. No significant differences were observed between geographically disparate networks within this review. The assumption is that the $594 \mathrm{mi2}$ environment represented within the $A B M$ is large enough to capture any given agents entire friendship network (i.e., all 5 people live within the studied area).

- The strength of a given social connection $S_{i q}$ is randomly assigned such that $S_{i q} \in(0,1]$. This random assignment is in keeping with research conducted by Onnela et al. [3] who found the strength of ties - 
quantified as the number of calls or texts between members of a phone network - to be independent of distance. Within the ABM, tie strength will be assumed to be symmetrical. That is, the strength of influence exerted by agent $i$ on agent $j$ is the same as that exerted by agent $j$ on agent $i$. This process assumes that Onnela et al's work [3] exploring tie strength within the context of a mobile phone network is generalizable to the older population and that symmetry with respect to tie strength approximates the nature of real-world relations.

\section{References}

1. Wrzus, C., et al., Social network changes and life events across the life span: a meta-analysis. Psychol Bull, 2013. 139(1): p. 5380.

2. Lambiotte, R., et al., Geographical dispersal of mobile communication networks. Physica A: Statistical Mechanics and its Applications, 2008. 387(21): p. 5317-5325.

3. Onnela, J.-P., et al., Geographic Constraints on Social Network Groups. PLOS ONE, 2011. 6(4): p. e16939. 


\section{Supplement A4: Model Rules}

\section{Drinking behavior}

A given agent's drinking status (or decision to either drink excessively, or not) is probabilistically determined using a drinking rule. In keeping with the literature, this probability $p\left(A_{i t}\right)$ may be expressed as a function of the combined influence of seven determinants spanning individual, social and environmental domains. Specifically, the likelihood that agent $i$ drinks excessively at any given time $t$ is shaped by: 1 ) an affinity for excessive alcohol consumption - characterized by a first-order autoregressive process - wherein an agent's affinity for excessive alcohol use in the preceding time step $p\left(A_{i t-1}\right)$ serves as a predictor of current affinity; 2 ) their current predisposition toward developing depression $\left.p\left(D_{i t}\right) ; 3\right)$ the drinking status and strength of ties to drinkers within their personal network $\left.f\left(n A D_{S n_{i}}, S_{A i}\right) ; 4\right)$ cohabitation status and the alcohol consumption status of the cohabitant/ spouse $\left.f\left(S p_{i}, S p_{A i}\right) ; 5\right)$ the time taken to access their nearest alcohol retailer $p\left(W t_{\text {inr }}\right)$; and 6) the relative cost of alcohol $f\left(A p, w_{i}\right)$ :

$\forall i \in P$,

$$
p\left(A_{i t}\right)=f\left(f\left(p\left(A_{i t-1}\right)\right)+f\left(p\left(D_{i t}\right)\right)+f\left(n A D_{S n_{i}}, S_{A i}\right)+f\left(S p_{i}, S p_{A i}\right)+f\left(W t_{i n r}\right)+f\left(A p, w_{i}\right)\right)
$$

Each of the components comprising this function is described below. The depression component is described in a separate section entitled 'Depression Rule'.

1) The contribution of network influences on an agent's affinity for excessive drinking is determined both by the proportion of drinkers in agent $i$ 's personal network as well as the relative strength of the connections between agent $i$ and drinking members of their personal network.

$$
f\left(n A D_{S n_{i}}, S_{A i}\right)=\left(\frac{n A D_{S n_{i}}}{n_{S n_{i}}}\right) \cdot\left(\frac{\sum_{A i \in S n_{i}} S_{A i}}{\sum_{q \in S n_{i}} S_{q}}\right)
$$

$n A D_{S n_{i}}=$ number of drinkers in agent $i^{\prime}$ s personal network, where $n A D_{S n_{i}}$ is a positive integer

$n_{S n_{i}}=$ number of people in agent $i$ 's personal network, where $n_{S n_{i}}>0$

$S_{A i}=$ strength of tie between agent $i$ and agents with excessive alcohol consumption in $i^{\prime}$ s personal network

$S_{q}=$ strength of tie between agent $i$ and any given agent $q$ in its personal network

2) The presence or absence of a spouse or cohabitant, as well as their alcohol consumption behavior, is considered in the alcohol decision rule. This is in keeping with research reporting a positive association between marital status and cohabitation, and excessive alcohol consumption in certain contexts [1-3]. An agent's likelihood of drinking to excess is represented by the below equation. Keeping all other factors influencing drinking behavior constant, this equation expresses that, in the model, an agent with a cohabitant/ spouse who drinks is more likely to consume alcohol to excess, than one with a cohabitant/ spouse who does not drink, and one living alone (in descending order of likelihood).

$$
f\left(S p_{i}, S p_{A i}\right)=\frac{\left(S p_{i}+S p_{A i}\right)}{2}
$$

$S p_{i}=$ agent $i^{\prime}$ s cohabitation status (if lives with someone $=1$; else $=0$ )

$S p_{A i}=$ agent $i$ 's cohabitant's alcohol status (if cohabitant drinks to excess $=1$; else $=0$ ) 
3) The proximity to alcohol retail outlets, characterized by travel time, represents an important environmental determinant of alcohol consumption. Within the model, the probability $p\left(W t_{i n r}\right)$ of accessing the nearest alcohol retailer to purchase alcohol is expressed using a simplified version of Huff's (1964) model (cited in [4]) which assumes that the probability of walking to the nearest retailer decays exponentially with increasing distance:

$$
p\left(W t_{i n r}\right)=\left(\frac{e^{\frac{1}{W t_{i n r}}}}{\sum_{r \in R_{i}} e^{\frac{1}{W t_{i n r}}}}\right)
$$

$W t_{\text {inr }}=$ agent $i$ 's walk time to nearest alcohol retailer $r$ (calculated by dividing the distance between agent $i$ and the nearest alcohol retailer by it's walking speed), where $W t_{i n r} \in \mathbb{R}^{+}$.

Huff's model has been used in other ABM studies, including the model developed by Huang \& Levinson [4] where its purpose was to characterize the probability that a customer chooses to shop at a specific retailer, given a number of alternatives. In the context of Huang \& Levinson's model [4], this choice was based on a retailer's attractiveness, which was operationalized as a function of the distance between the customer and the retailer and other unobservable factors. For simplicity, in the context of our model, only the distance between agent and alcohol retail outlets was used as a determinant of outlet selection. The minimum walking time, which reflects a situation in which an agent and an alcohol outlet are co-located, is sat at 5 minutes. That is, in the case of co-location, a minimum distance between agent and outlet is assumed to be 0.25 miles (or half the length of cell in Netlogo). The corresponding walking time therefore is calculated as this distance divided by the average walking speed of agents (i.e., $0.25 \mathrm{mi} / 2.98 \mathrm{mi} / \mathrm{hr}=0.0839 \mathrm{hrs} \sim 5 \mathrm{~min}$ ).

4) The influence of alcohol cost on the likelihood of excessive alcohol consumption is considered uniquely for each agent and expressed as a relative cost. That is, the weekly alcohol cost of an excessive drinker (i.e., someone drinking $>7$ standard drinks per week according to US recommendations for those $>60$ years old) is represented as a fraction of total weekly income:

$$
f\left(A p, w_{i}\right)=\left(1-\frac{A p}{w_{i}}\right)
$$

$w_{i}=$ weekly income of agent $i$ expressed in USD $/ \mathrm{hr}$

$A p=$ price of 8 standard drinks of alcohol (USD) = USD13.44

According to DiLoreto et al. [5], the average price per ounce (or $28.3 \mathrm{~g}$ ) of alcohol is $\$ 3.36$. Given that 1 US standard drink $=14 \mathrm{~g}$ of pure alcohol, 1 ounce = approx. 2 standard drinks. The price per standard drink according to this study therefore is $\$ 1.68$, which equates to a total cost of at least $\$ 13.44 \mathrm{pw}$ for an older adult consuming 8 standard drinks (i.e., drinking excessively according to US recommendations for those $>60$ years old). 
On the whole, in the context of a social drinking culture, the probability $p\left(A_{i t}\right)$ that any given agent $i$ engages in excessive alcohol consumption, at any given time $t$, is influenced by the aforementioned factors and calculated using the equation featured below. This probability is used to determine the excessive alcohol consumption status $A_{i t}$ of each agent within the model (i.e., as either drinking excessively or not drinking excessively). The greater the probability $p\left(A_{i t}\right)$, the more likely a given agent is to be assigned excessive drinking status. The proportion of agents drinking excessively is tracked throughout the life of the simulation.

$\forall i \in P$,

$$
\begin{gathered}
p\left(A_{i t}\right)=x\left(p\left(A_{i t-1}\right)+\delta p\left(D_{i t}\right)+w S\left(\left(\frac{n A D_{S n_{i}}}{n_{S n_{i}}}\right) \cdot\left(\frac{\sum_{A i \in S n_{i}} S_{A i}}{\sum_{q \in S n_{i}} S_{q}}\right)+\frac{\left(S p_{i}+S p_{A i}\right)}{2}\right)\right. \\
\left.+w E\left(\left(\frac{e^{\frac{1}{W t_{i n r}}}}{\sum_{r \in R_{i}} e^{\frac{1}{W t_{\text {inr }}}}}\right)+\left(1-\frac{A p}{w_{i}}\right)\right)\right)
\end{gathered}
$$

Where $x$ normalizes the function such that it is expressed as a probability with $p\left(A_{i t}\right) \in[0,1]$ :

$$
x=\frac{\delta \cdot w S \cdot w E}{w S \cdot w E \cdot(\delta+1)+\delta(2 w E+2 w S)}
$$

$p\left(A_{i t-1}\right)=$ agent $i$ 's past affinity for excessive alcohol consumption, where $p\left(A_{i t-1}\right) \in[0,1]$

$p\left(D_{i t}\right)=$ agent $i$ 's current predisposition toward developing depression, where $p\left(D_{i t}\right) \in[0,1]$

$n A D_{S n_{i}}=$ number of drinkers in agent $i^{\prime}$ s personal network, where $n A D_{S n_{i}}$ is a positive integer

$n_{S n_{i}}=$ number of people in agent $i$ 's personal network, where $n_{S n_{i}}>0$

$S_{A i}=$ strength of tie between agent $i$ and agent's with excessive alcohol consumption in $i$ 's personal network

$S_{i q}=$ strength of tie between agent $i$ and any given agent $q$ in its personal network

$S p_{i}=$ agent $i$ 's cohabitation status (if lives with someone $=1$; else $=0$ )

$S p_{A i}=$ agent $i$ 's cohabitant's alcohol status (if cohabitant drinks to excess $=1$; else $=0$ )

$W t_{\text {inr }}=$ agent $i$ 's walk time to nearest alcohol retailer $r$ (calculated by dividing the distance between agent $i$ and the nearest alcohol retailer by it's walking speed), where $W t_{i n r} \geq 0.0839$ (as explained at the end of page 9)

$A p=$ price of 8 standard drinks of alcohol (USD) $=\$ 13.44$

$w_{i}=$ weekly income of agent $i$ expressed in USD/hr

Calibrated parameters:

$\delta=$ weight of influence of depression on excessive alcohol consumption likelihood, where $\delta \in \mathbb{R}^{+}$

$w S=$ weight of social influence on excessive alcohol consumption likelihood, where $w S \in \mathbb{R}^{+}$

$w E=$ weight of environmental influence on excessive alcohol consumption likelihood, where $w E \in \mathbb{R}^{+}$ 


\section{Evolution of depression}

The temporal nature and shape of depression prevalence trajectories in the face of time-varying alcohol use patterns among older adults is poorly understood. Given this empirical gap, the trajectory representing an older adult's predisposition for developing depression within the ABM was modelled as a sigmoid curve. That is, a trajectory wherein the likelihood of developing depression is initially stable/ slowly increasing, then undergoes a phase of rapid growth which gradually decreases as the probability of depression approaches the asymptote (i.e., at $p\left(D_{i t}\right)=1$ ).

The functional form corresponding to the assumed depression trajectory is represented by:

$$
\forall i \in P, \quad p\left(D_{i t}\right)=\left(1+\varphi e^{\frac{-p\left(A_{i t}\right) p\left(D_{i t-1}\right) t}{\lambda}}\right)^{-1}
$$

Where,

An agent with no personal connections has $\lambda=1$

An agent with a personal network has $\lambda=\gamma\left(n_{S n_{i}}+\overline{s_{q}}\right)$

Definition of terms:

$p\left(D_{i t}\right)=$ agent $i$ 's current predisposition toward being depressed, where $p\left(D_{i t}\right) \in[0,1]$

$p\left(D_{i t-1}\right)=$ agent $i$ 's past predisposition for being depressed, where $p\left(D_{i t-1}\right) \in[0,1]$

$p\left(A_{i t}\right)=$ agent $i$ 's current affinity for excessive alcohol consumption, where $p\left(A_{i t}\right) \in[0,1]$

$\lambda=$ depression rate dampening term, where $\lambda \geq \mathbf{1}$

$n_{S n_{i}}=$ number of people in agent $i$ 's personal network, where $n_{S n_{i}}>0$

$\overline{S_{q}}=$ mean tie strength to members of own personal network

$t=$ time (weeks)

Calibrated parameters:

$\gamma=$ weight that determines the extent to which personal networks dampen depression growth, where $\gamma \in \mathbb{R}^{+}$ $\varphi=$ determines the $\mathrm{y}$-axis intercept of the $p\left(D_{i t}\right)$ growth function.

NOTE: $\varphi$ determines the $y$-axis intercept i.e., the greater the value, the smaller the $p\left(D_{i t}\right)$ intercept. Variables $p\left(A_{i t}\right), p\left(D_{i t-1}\right), n_{S n_{i}}$ and $\overline{s_{q}}$ collectively govern the $p\left(D_{i t}\right)$ growth rate. That is, the greater the values of $p\left(A_{i t}\right)$ and $p\left(D_{i t-1}\right)$, the higher the growth rate. Variables $n_{S n_{i}}, \overline{s_{q}}$ and $\gamma$ are growth scaling terms; the greater the value of these terms, the longer it takes for $p\left(D_{i t}\right)$ to reach its maximum value (i.e, the slower the rate of growth). 


\section{References}

1. Hajat, S., et al., Patterns and determinants of alcohol consumption in people aged 75 years and older: results from the MRC trial of assessment and management of older people in the community. Age Ageing, 2004. 33(2): p. $170-7$.

2. Kharicha, K., et al., Health risk appraisal in older people 1: are older people living alone an "at-risk" group? Br J Gen Pract, 2007. 57(537): p. 271-6.

3. Weyerer, S., et al., At-risk alcohol drinking in primary care patients aged 75 years and older. Int J Geriatr Psychiatry, 2009. 24(12): p. 1376-85.

4. Huang, A. and D. Levinson, Why Retailers Cluster: An Agent Model of Location Choice on Supply Chains. Environment and Planning B: Planning and Design, 2011. 38(1): p. 82-94.

5. DiLoreto, J.T., et al., Assessment of the Average Price and Ethanol Content of Alcoholic Beverages by Brand - United States, 2011. Alcoholism, Clinical and Experimental Research, 2012. 36(7): p. 1288-1297. 